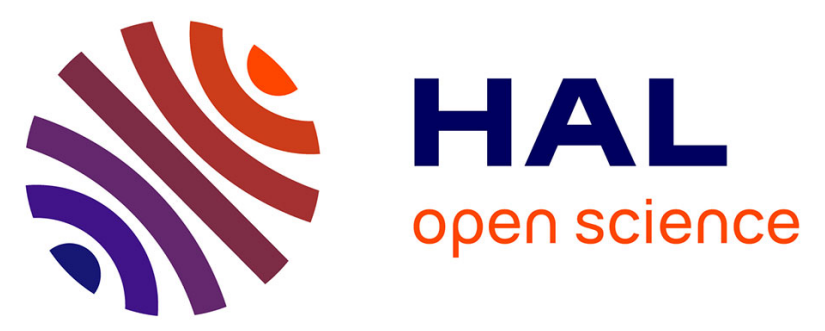

\title{
Improvement of lean blow out performance of spray and premixed swirled flames using nanosecond repetitively pulsed discharges
}

Guillaume Vignat, Nicolas Minesi, Preethi Rajendram Soundararajan, Daniel Durox, Antoine Renaud, Victorien Blanchard, Christophe O Laux, Sébastien Candel

\section{To cite this version:}

Guillaume Vignat, Nicolas Minesi, Preethi Rajendram Soundararajan, Daniel Durox, Antoine Renaud, et al.. Improvement of lean blow out performance of spray and premixed swirled flames using nanosecond repetitively pulsed discharges. Proceedings of the Combustion Institute, 2021, 38 (4), pp.6559-6566. 10.1016/j.proci.2020.06.136 . hal-03117288

\section{HAL Id: hal-03117288 \\ https://hal.science/hal-03117288}

Submitted on 21 Jan 2021

HAL is a multi-disciplinary open access archive for the deposit and dissemination of scientific research documents, whether they are published or not. The documents may come from teaching and research institutions in France or abroad, or from public or private research centers.
L'archive ouverte pluridisciplinaire HAL, est destinée au dépôt et à la diffusion de documents scientifiques de niveau recherche, publiés ou non, émanant des établissements d'enseignement et de recherche français ou étrangers, des laboratoires publics ou privés. 


\title{
Improvement of Lean Blow Out Performance of Spray and Premixed Swirled Flames using Nanosecond Repetitively Pulsed Discharges
}

\author{
Guillaume Vignat ${ }^{\mathrm{a}, *}$, Nicolas Minesi ${ }^{\mathrm{a}}$, Preethi Rajendram Soundararajan ${ }^{\mathrm{a}}$, Daniel Durox ${ }^{\mathrm{a}}$, Antoine Renaud ${ }^{\mathrm{a}}$, \\ Victorien Blanchard ${ }^{\mathrm{a}}$, Christophe O. Laux ${ }^{\mathrm{a}}$, Sébastien Candel $^{\mathrm{a}}$ \\ ${ }^{a}$ Laboratoire EM2C, CNRS, CentraleSupélec, Université Paris-Saclay, 3 rue Joliot Curie, 91192 Gif-sur-Yvette, France
}

\begin{abstract}
Plasma-Assisted Combustion (PAC) has shown potential in improving the ignition, extinction, and dynamic performance of combustion systems. In this work, Nanosecond Repetitively Pulsed (NRP) spark discharges are applied to extend the lean blow out limit of the SICCA-Spray burner. This laboratory-scale atmospheric test rig is equipped with a swirl spray injector representing in an idealized fashion a single sector of a gas turbine. Three fuels and injection conditions are considered: perfectly premixed methane-air, liquid heptane, and liquid dodecane injected as hollow cone sprays. The optimal electrode position that extends the LBO limit is found to be near the external edge of the outer recirculation zone (ORZ). Spectroscopic measurements show that the NRP sparks produce atomic species and heat the gas above the adiabatic flame temperature. High-speed chemiluminescence images of blow out sequences indicate that the flame evolves similarly for all three fuels from "M" or "V" shapes prevailing at $\phi=0.9$ to a configuration where chemical conversion also takes place in the ORZ at $\phi=0.63$. A low frequency combustion oscillation arises near the LBO limit $(\phi=0.57)$. Spray flames blow out at this point, while the plasma-assisted ones continue to burn. It is shown that PAC provides a significant improvement of the extinction performance, in particular when operating with liquid fuel spray injection.
\end{abstract}

Keywords: Plasma-assisted combustion; Lean blow out; Swirled spray flames; Combustion enhancement; Non-equilibrium plasma

\section{Colloquium: New Concepts}

Length of the paper determined using Method 2.

Total length of the paper: less than 8 pages

The authors will pay color reproduction charges if applicable.

\footnotetext{
${ }^{*}$ Corresponding author:

Email address: guillaume.vignat@centralesupelec.fr (Guillaume Vignat) 


\section{Introduction}

Premixed and pre-vaporized lean combustion allows for reduced pollutant emissions in gas turbines and aeroengines. In order to control this type of combustion, manufacturers rely to a large extent on advances in swirling injector design to anchor compact flames with a high degree of air dilution. Although the lean stability performance of traditional swirling injectors is already quite good, an increase of the lean blow out (LBO) margin is still desirable, especially for operational and safety reasons [1]. For twenty years, plasma-assisted combustion (PAC) has been considered to improve three key areas of combustion: ignition [2], combustion instabilities [3, 4] and extinction [5, 6]. Recent works in these directions are reviewed in [7-10].

Non-equilibrium NRP (Nanosecond Repetitively Pulsed) spark discharges last a few nanoseconds, with an overvoltage of a few kilovolts. Applied at a repetition rate in the 10 to $100 \mathrm{kHz}$ range in a combustible mixture, they produce thermal, chemical, and hydrodynamic effects [11-13] that promote the combustion process $[2,4,6,14]$. These benefits have been extensively demonstrated at low and atmospheric pressures, and some recent studies $[15,16]$ have also shown positive effects for the ignition of lean mixtures at pressures up to 16 bar. It was shown $[14,17]$ that the discharge serves as a localized source of heat (thermal effect) and active species (chemical effect), anchoring the flame even in very lean mixtures. In a recent study, Kong et al. [18] used a continuous AC-powered plasma in a methaneair flame and suggested that the predominant contribution might be from thermal effects, probably due to the higher duration and power of their discharge.

In most practical systems, the LBO limit is dictated by the design of the injector and operating parameters. NRP discharges have successfully been used to extend the LBO limit in laboratory scale test rigs, often with minimal modifications to the combustor. The electrode is generally located on the centerline of the burner, close to the injector outlet, inside a gas recirculation zone with low flow velocities $[3,5,6,19]$. Even in very lean mixtures, well below the extinction limit, a reaction zone is formed in the vicinity of the electrode. The NRP discharges thus establish a pilot flame that extends the LBO limit of the combustor. It is likely, however, that combustion is incomplete under these conditions [14].

In practical applications, specifically in aero-engines, positioning the electrode on the injector centerline may not be practical. The solid electrode will perturb the flow and symmetry, create additional flame anchoring points and also get degraded by the resulting heat fluxes.
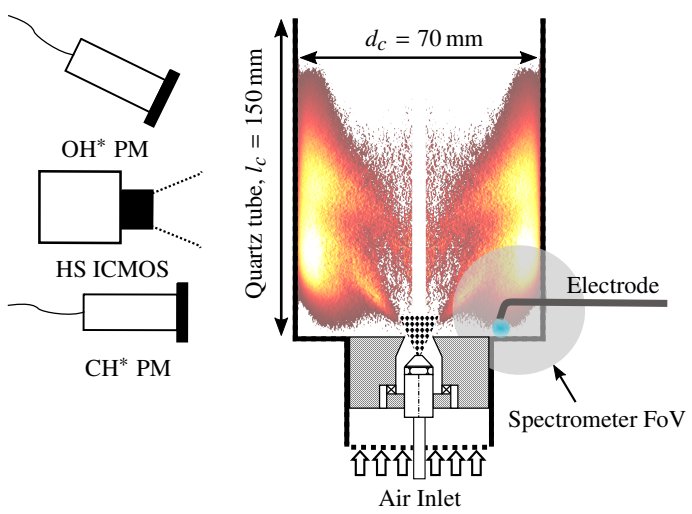

Figure 1: Schematic view of the SICCA-Spray burner. The air plenum is cut for concision. Chemiluminescence diagnostics include a high-speed intensified camera (HS ICMOS) and two photomultipliers (PM). An Abel transformed flame image (see Fig. 5) acquired at an equivalence ratio $\phi=0.63$ is shown in the background. A gray disk qualitatively indicates the field of view (FoV) of the spectrometer. The electrode is to scale with the flame image.

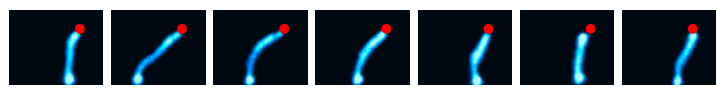

Figure 2: Direct imaging of the plasma discharge using the high-speed camera at $500 \mathrm{fps}$ (false colors). Exposure time is $50 \mu$ s to capture a single discharge. The red dots correspond to the tip of the electrode, the bottom of the image to the combustor backplane.

Moreover, liquid fuel atomizers are commonly located on the centerline to ensure a homogeneous spray distribution, and the discharge might form between the electrode and the atomizer head. To avoid damaging this sensitive component, in the present study, the electrode is placed close to the lateral wall and the chamber backplane, in the outer recirculation zone (ORZ). Thus, the discharges will occur in an area where the reactive species have sufficient time to mix with the fuel and oxidizer.

In this work, three fuels are considered: premixed methane-air (for a baseline), liquid heptane and liquid dodecane, which is comparatively less volatile [20]. We show that the LBO limit of these swirling flames is extended with NRP discharges.

\section{Experimental Setup}

\subsection{The SICCA-Spray Combustor}

Experiments are carried out at atmospheric pressure in the SICCA-Spray combustor which is slightly modified compared to previous spray ignition investigations [20]. As shown in Fig. 1, the system consists of an air plenum followed by a swirling injection system (gray area) comprising a tangential channel swirler that leads to a convergent section with a final radius 
$r_{i n j}=4 \mathrm{~mm}$. This injector has a measured swirl number of 0.68 [20]. Liquid fuel is injected as a hollow cone spray (diamond-patterned triangle) by a simplex atomizer. When the system operates in the premixed mode, methane is mixed with the air flow using a cyclonic mixing chamber located $3 \mathrm{~m}$ upstream of the air plenum. A compact flame is stabilized downstream of the dump plane inside a transparent quartz confinement tube. Spray characterization, performed at the nominal operating condition ( $t_{0}$ in Tab. 1 ), indicates that for both liquid fuels the mean Sauter diameter of droplets is $D_{32} \approx 30 \mu \mathrm{m}$ [20]. NRP discharges are created between the tip of an Inconel electrode and the combustor backplane (Fig. 2). The electrode tip is located $5 \mathrm{~mm}$ above the backplane and $24 \mathrm{~mm}$ from the centerline of the combustor, except in Sec. 4 where its position is varied. Pulses of 10-ns duration with an incident amplitude of $5 \mathrm{kV}$ are generated by a FPG 10-30NM10 generator (FID Technology) at a repetition rate of $20 \mathrm{kHz}$.

\subsection{Measurement Equipment}

A 6-meter long coaxial cable ( $75 \Omega$ impedance) connects the generator and the electrode. A high voltage probe (Lecroy PPE20kV) and a current probe (Pearson 6585) are placed midway on the cable and are used to monitor the deposited energy on an oscilloscope (Lecroy HDO 6104) [21]. Typical voltage and current curves are shown in Fig. 3. The deposited energy can be calculated from these curves because it has been verified that no energy is lost in the cable and because radiative losses are negligible [22]. In this study, the voltage is adjusted for every configuration so that the deposited energy remains constant at $5.00 \mathrm{~mJ} \pm 0.25 \mathrm{~mJ}$, corresponding to an average electrical power of $100 \mathrm{~W} \pm 5 \mathrm{~W}$.

Mass flow controllers (Bronkhorst EL-Flow) with a relative accuracy of $\pm 7.5 \%$ and a repeatability better than $\pm 2 \%$ monitor the flows of air and methane. A Bronkhorst CORI-Flow system is used for the liquid fuels (relative accuracy $\pm 2 \%$, repeatability better than $\pm 0.75 \%$ ). A high-speed intensified camera records the flame images (Photron FastCam APX-i2, $512 \times 1024$ pixels, 10-bit gray level depth, 500 images per second with an exposure time of $2 \mathrm{~ms}$ ). It is equipped with a $45 \mathrm{~mm}$ lens and an optical bandpass filter centered at $431 \mathrm{~nm}$ to capture the emission of the $\mathrm{CH}^{*}$ radical. The field of view encompasses the whole combustion chamber, from the dump plane to the quartz tube outlet. Two photomultipliers (PM) measure the chemiluminescence signal from the flame. One is equipped with an optical bandpass interference filter centered at $308 \mathrm{~nm}$ to capture the emission from the $\mathrm{OH}^{*}$ radical in the flame and

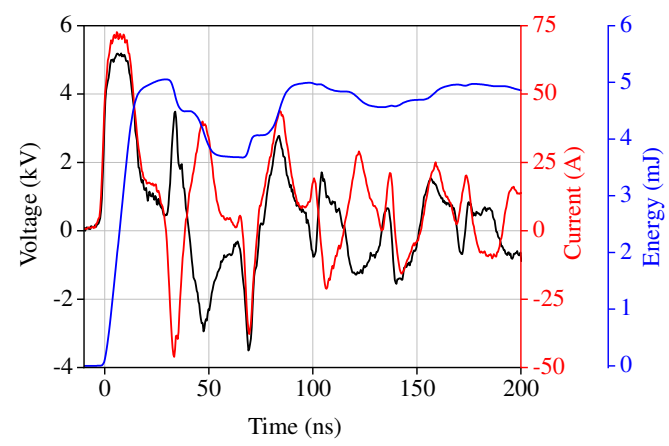

Figure 3: Voltage (black) and current (red) traces recorded with NRP discharges in a dodecane flame. The energy curve (blue) is the integral of the current and voltage product. In this example, $5.00 \mathrm{~mJ} \pm 0.25 \mathrm{~mJ}$ is sent by the pulser and $1.50 \mathrm{~mJ} \pm 0.25 \mathrm{~mJ}$ is initially reflected. This energy is deposited during subsequent reflections at $t=90 \mathrm{~ns}$ and $t=180 \mathrm{~ns}$. For detailed descriptions of the oscillograms, see [11,21].

the other with a filter centered at $431 \mathrm{~nm}$ for the emission of $\mathrm{CH}^{*}$ radicals. These sensors integrate the light emission from the whole combustor volume. Their signals, along with the flowrates, are recorded at $2 \mathrm{kHz}$. The PM signals are a qualitative indicator of the instantaneous heat release rate of the flame, and are used to detect LBO when these signals drop to zero. When the discharge is active, other excited species, notably $\mathrm{N}_{2}^{*}$, emit in the same spectral ranges, and electromagnetic noise, captured by the acquisition chain, is present. This is managed by appropriate electromagnetic shielding, recording the signal with a delay of $35 \mu$ s with respect to the pulsed discharge (using a BNC Model 577 gate-and-delay generator), and applying a low pass filter in post-processing. This is found sufficient to reliably detect LBO even in the presence of the discharge. An OceanOptics Maya2000Pro deep-UV spectrometer is used to analyze the spontaneous emission from the flame and the plasma. The optical train consists of a small lens and an optical fiber. The field of view (FoV) schematically shown in Fig. 1 encompasses the entire discharge area and some of the ORZ with an integration time including several discharges $(\approx 1 \mathrm{~ms})$. Therefore, the spectra are representative of the brightest region of the plasma (the core) at the peak of the emission (end of the discharge).

\subsection{Characterization of the plasma}

In addition to the images in Fig. 2 and the electrical characterization in Fig. 3, Optical Emission Spectroscopy (OES) of the PAC dodecane flame is performed at four different flame operating conditions $(\phi=$ $0.87,0.65,0.60$ and 0.53$)$. The acquired spectra displayed in Fig. 4 give a qualitative idea of the species 


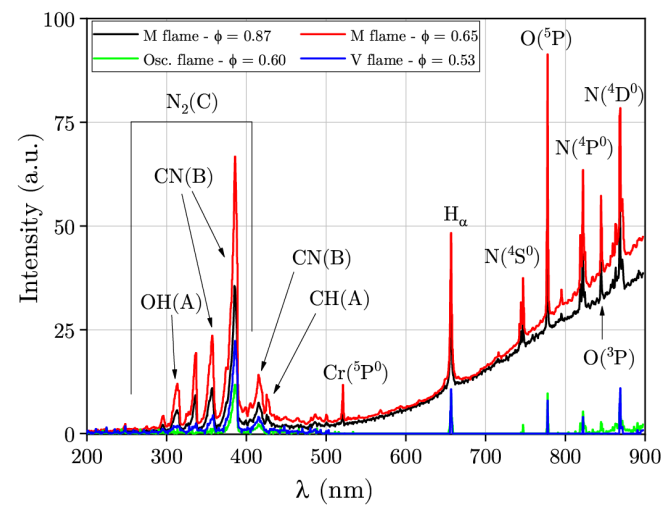

Figure 4: Typical emission spectra recorded in a dodecane flame assisted by NRP discharges $(\phi=0.87,0.65,0.60$ and 0.53$)$. At $520 \mathrm{~nm}$ emission from $\mathrm{Cr}$ is visible (not to be confused for $\mathrm{C}_{2}$ Swan emission). It originates from the erosion of the Inconel electrode $(\approx 20 \% \mathrm{Cr}$ ). For wavelengths longer than $500 \mathrm{~nm}$, a continuum associated with thermal radiation from the burner and the quartz tube is present.

excited and produced by the discharge and the flame. Typical combustion species $\left(\mathrm{CH}^{*}\right.$ and $\left.\mathrm{OH}^{*}[23,24]\right)$ are identified in these PAC spectra as well as in the spectra without PAC (not shown here). Strong peaks arising from the emission of $\mathrm{CN}^{*}$ are found, a feature also reported by Kim et al. [25] in a plasma-assisted premixed methane-air jet flame. No significant emission from $\mathrm{C}_{2}^{*}$ is detected. Atomic emission from oxygen $\mathrm{O}^{*}$, nitrogen $\mathrm{N}^{*}$, and hydrogen $\mathrm{H}_{\alpha}$ is observed. These features show that the NRP discharges dissociate $\mathrm{O}_{2}, \mathrm{~N}_{2}$ and possibly $\mathrm{CO}_{2}, \mathrm{H}_{2} \mathrm{O}$ and the fuel.

Stark broadening of the $\mathrm{H}_{\alpha}$ line at $656 \mathrm{~nm}$ is used to determine the electron number density $\left(n_{e}\right)$ of the plasma [26]. At $\phi=0.87$ and 0.65 (attached stable flames), $n_{e}=(1.4 \pm 0.2) \times 10^{17} \mathrm{~cm}^{-3}$, which corresponds to a degree of ionization about $10 \%$. Several peaks are associated with the emission of $\mathrm{N}_{2}(\mathrm{C})$. Using SPECAIR [23], the rotational and vibrational temperatures are estimated: $T_{r o t}=(3500 \pm 500) \mathrm{K}$ and $T_{v i b}=(8000 \pm 1000) \mathrm{K}$. As the emission is averaged in space and time by the spectrometer, the emission of $\mathrm{N}_{2}(\mathrm{C})$ is representative of the hottest region (center) of the plasma at the end of the pulse. At this instant, $\mathrm{N}_{2}(\mathrm{C})$ is populated by electron impact and therefore its rotational distribution mirrors that of $\mathrm{N}_{2}(\mathrm{X})$ [12]. Owing to fast rotationaltranslational relaxation at atmospheric pressure, the rotational temperature of $\mathrm{N}_{2}(\mathrm{X})$ is close to the gas temperature, therefore $T_{\text {gas,plasma }} \simeq T_{\text {rot }}=(3500 \pm 500) \mathrm{K}$ is representative of the peak temperature at the end of the discharge. The quenching of $\mathrm{N}_{2}$ excited states by $\mathrm{O}_{2}$ is responsible for the increase in temperature and the dissociation of $\mathrm{O}_{2}$ [12]. Both effects are favorable for the flammability of the combustible mixture.
Table 1: Operating conditions for all fuels at the start of the air flow linear ramp $\left(t_{0}\right)$ and at the end $\left(t_{\infty}=40 \mathrm{~s}\right)$. The bulk velocity $u_{b}$ is defined at cold thermal conditions as $u_{b}=\dot{m}_{\text {gas }} / \pi \rho r_{i n j}^{2}$. The fuel mass flow rate, thermal power and global equivalence ratio are respectively designated by $\dot{m}_{f u e l}, \mathcal{P}$ and $\phi$.

\begin{tabular}{ccccccc}
\hline & $\dot{m}_{\text {fuel }}$ & $\mathcal{P}$ & \multicolumn{2}{c}{$\phi$} & \multicolumn{3}{c}{$u_{b}\left(\mathrm{~m} \mathrm{~s}^{-1}\right)$} \\
& $\left(\mathrm{g} \mathrm{h}^{-1}\right)$ & $(\mathrm{kW})$ & $t_{0}$ & $t_{\infty}$ & $t_{0}$ & $t_{\infty}$ \\
\hline $\mathrm{CH}_{4}$ & 359 & 4.98 & 0.88 & 0.46 & 35 & 65 \\
$\mathrm{C}_{7} \mathrm{H}_{16}$ & 400 & 4.95 & 0.87 & 0.45 & 32 & 62 \\
$\mathrm{C}_{12} \mathrm{H}_{26}$ & 405 & 4.97 & 0.87 & 0.45 & 32 & 62 \\
\hline
\end{tabular}

The temperature in the plasma $T_{\text {gas,plasma }} \approx 3500 \mathrm{~K}$, higher than the adiabatic flame temperature $\left(T_{a d}<\right.$ $2100 \mathrm{~K}$ ), and the dissociation of $\mathrm{O}_{2}$ indicate that this discharge is neither an NRP-corona nor an NRP-glow discharge [13]. $\quad n_{e}$ is between the values reported for nonequilibrium NRP-sparks [12], and for thermal sparks [21]. As neither $\mathrm{N}^{+}$emission $(500 \mathrm{~nm})$ nor an electron continuum is observed in the spectra, the NRPspark is necessarily of the nonequilibrium type.

\subsection{Lean Blow Out Procedure}

To avoid changing the fuel atomization properties, which are sensitive to the flow rate for simplex atomizers [27], the fuel flow rates are kept constant. They are chosen so that the thermal power is almost the same for all fuels at $\mathcal{P} \approx 5 \mathrm{~kW}$. The ratio of electrical (NRP) to thermal (combustion) power is therefore equal to $2 \%$ for all cases. The LBO limit is determined by linearly varying the air flow rate, starting from the nominal, wellcharacterized operating point of $\dot{m}_{\text {air }}=1.94 \mathrm{~g} \mathrm{~s}^{-1}$ [20] and going up to $\dot{m}_{\text {air }}=3.77 \mathrm{~g} \mathrm{~s}^{-1}$ over a time period of $40 \mathrm{~s}$. Before starting the air ramp, in order to ensure reproducibility, the burner is operated at the steady nominal operating point until thermal equilibrium is reached. The operating conditions are summarized in Tab. 1.

\section{Experimental Results for Different Fuels}

The flame evolution during the air ramp, depicted in Fig. 5, shows flame images for both methane and heptane. Evolution of the flame shape is essentially the same for all three fuels with and without plasma. Starting from an "M" or "V" shaped flame at the nominal operating condition, the flame changes shape to burn both in the ORZ and at the top of the swirling jet at leaner operating points $(\phi \approx 0.64)$, leading to an "M+ORZ" shape. Soon after, the flame starts to oscillate at a frequency close to $12 \mathrm{~Hz}$ for methane $(\phi=0.58)$, and $7 \mathrm{~Hz}$ for liquid fuels $(\phi=0.57$ for heptane). These oscillations are investigated using the 


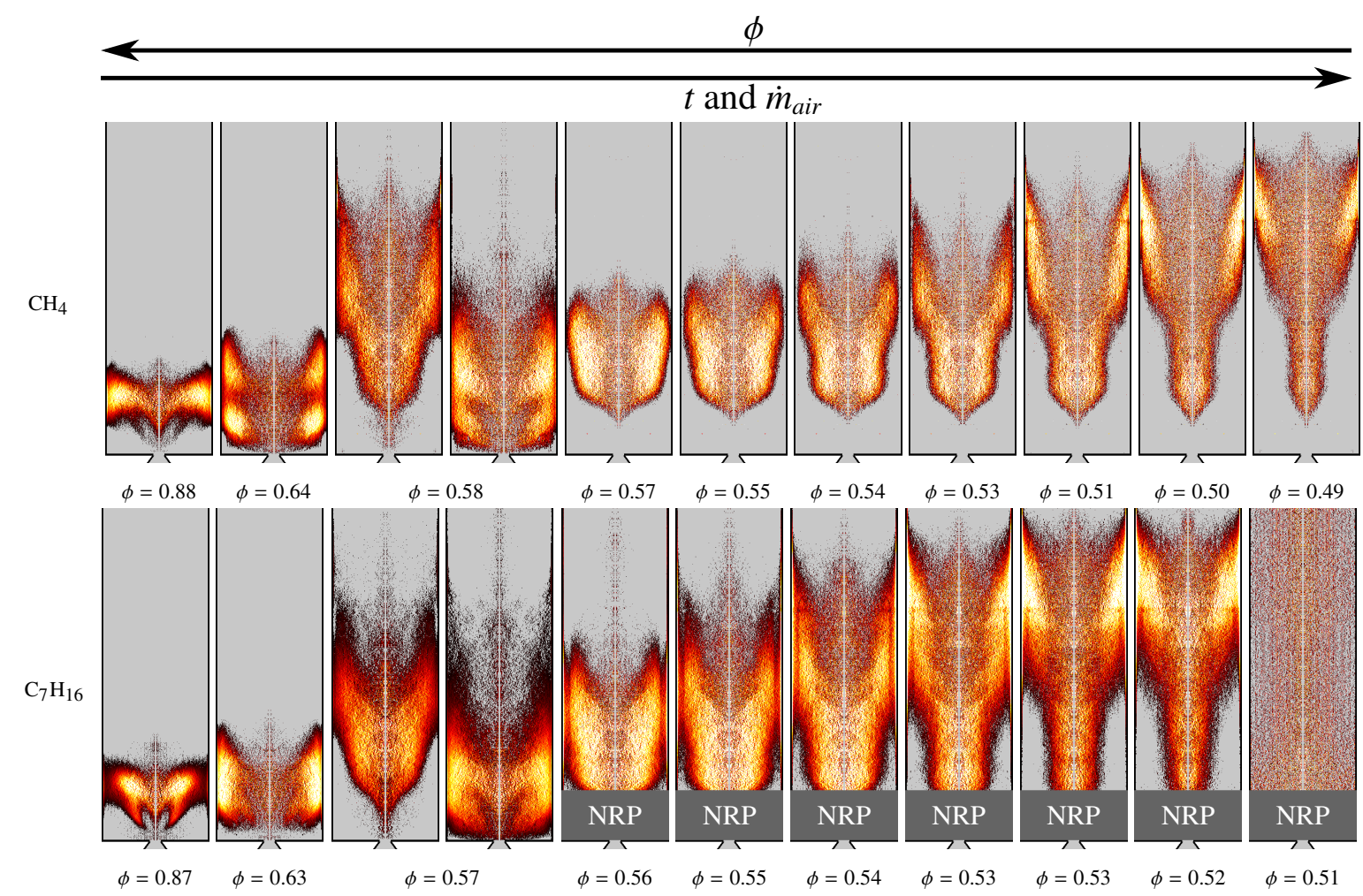

Figure 5: Chemiluminescence $\left(\mathrm{CH}^{*}\right)$ images acquired using the high-speed camera. An Abel transform is performed to aid the identification of the flame shape assuming azimuthal symmetry. From left to right, the air flow is increased starting at the nominal condition of Tab. 1. The first line shows the blow out sequence for a methane flame without PAC. The second line that for a heptane flame, without PAC down to $\phi=0.57$, and with PAC for leaner operating points. In the latter case, a darker band at the bottom of the combustor masks the luminosity of the discharges. The images are also noisier especially near the centerline. From $\phi=0.62$ up to $\phi=0.56$ for methane and from $\phi=0.60$ up to $\phi=0.55$ for heptane (without PAC), a low frequency oscillation is found (see Fig. 6). For those operating points, two opposite phase instants are shown. No change in flame shape or flame height is observed between PAC and non-assisted flames.

high speed camera. Images are processed using DMD (Dynamic Mode Decomposition [28]), and are shown as phase-averaged flame images in Fig. 6 for heptane. These low-frequency oscillations are essentially extinction and reignition in the ORZ, as the flame oscillates between an "M+ORZ" and a "tulip" shape. The ORZ reignites by the propagation of flame kernels from the downstream side to the ORZ. The overall evolution is similar for all three fuels during the oscillation, although the frequency is higher for methane. This type of lowfrequency oscillations occurring close to the LBO limit is investigated in [1]. DMD is also performed on the spark images (Fig. 2) acquired during the oscillation phase, but it shows no coherent motion of the spark at the frequency of the flame. These flame oscillations end either by LBO, or by stabilization of the flame in a fairly long "tulip" shape. As the air flow rate is increased, the "stem" part of the flame becomes longer, and the "petals" move downstream until LBO occurs. Flame oscillations between two stable flame regions are also
Table 2: Probability $\hat{p}$ of flame blow out during the oscillation phase for each fuel with and without PAC (lower is better). At least 10 experiments are performed for each case. The $95 \%$ statistical confidence interval is computed using the Clopper-Pearson method and is indicated in parenthesis.

\begin{tabular}{ccc}
\hline & $\hat{p}_{\text {not PAC }}$ & $\hat{p}_{\text {PAC }}$ \\
\hline $\mathrm{CH}_{4}$ & $0.13(-0.11,+0.26)$ & $0(+0.26)$ \\
$\mathrm{C}_{7} \mathrm{H}_{16}$ & $1.00(-0.21)$ & $0.27(-0.21,+0.34)$ \\
$\mathrm{C}_{12} \mathrm{H}_{26}$ & $1.00(-0.28)$ & $0.26(-0.17,+0.25)$ \\
\hline
\end{tabular}

reported by Kim et al. [5] during LBO characterization of a premixed swirling flame with PAC.

As indicated previously, after the oscillations the flame either suddenly blows out or continue to burn while the equivalence ratio decreases. Table 2 indicates the probability $\hat{p}$ of flame blow out during the oscillations for each fuel with and without PAC. The improvement is moderate for premixed methane and air, which already features good resistance to LBO without PAC. A statistically significant extension of the LBO 


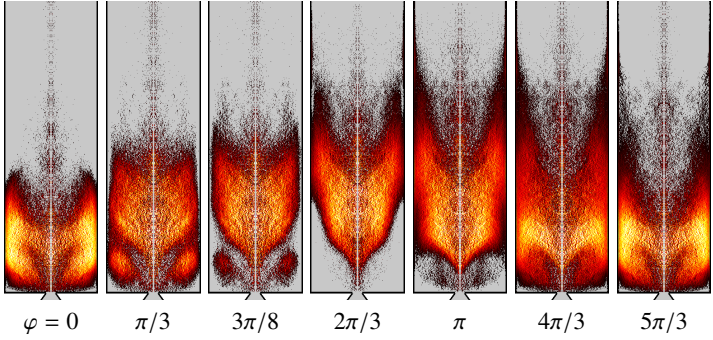

Figure 6: Phase averaged images of flame oscillation with heptane fuel ( $\phi=0.57$, not PAC). Flame images are acquired using the highspeed camera and are then processed using DMD, which shows a predominant mode at $7.5 \mathrm{~Hz}$. An Abel transform is applied.

is observed using PAC in heptane and dodecane spray flames. For these fuels, without PAC, the flame is systematically blown out during the oscillating phase, but is much more robust with NRP discharges, leading to a significant improvement of the LBO limit.

The improvement of the LBO limit with plasmaassistance is also represented in Fig. 7, where the histograms indicate the global equivalence ratio at LBO $\left(\phi_{L B O}\right)$ with (red) and without (black) NRP discharges. Figure 7 shows for each fuel the flame oscillation frequency $f_{o s c}$ as a function of $\phi$ (right axis, dots). In each case, a set of repeated experiments is presented. For all three fuels, the flame oscillation regime starts and ends at a leaner operating point with NRP discharges. Two observations can be drawn from these results: firstly, as $\phi$ decreases, there is a decrease in the oscillation frequency for all three fuels. Secondly, the frequency trend is similar with and without plasma assistance.

For methane, the end of the oscillating regime is nearly the same with and without PAC. The flame stabilizes as a "tulip" shape after the oscillation. For two of the tests without NRP discharges, one observes LBO during the oscillation phase. For heptane and dodecane, without plasma assistance, LBO always occurs during flame oscillations ${ }^{1}$. When the NRP discharges are turned on, the flame is sustained after the oscillation phase and blows out under leaner conditions ${ }^{2}$. The increased LBO limit with PAC is quantified in Fig. 8 for all three fuels. The LBO limit (brown) is extended by $\Delta \phi=0.05$ for both liquid fuels, and $\Delta \phi=0.018$ for methane. The beginning of the low frequency oscilla-

\footnotetext{
${ }^{1}$ If the NRP discharges are turned on immediately after the extinction, the flame does not reignite.

${ }^{2}$ If the NRP discharges are turned off once the flame overcomes the oscillating phase, the flame continues to burn until LBO at $\phi \approx$ 0.52 . This indicates that the "tulip" flame can exist without plasma. However, this state cannot be reached without NRP discharges and the extinction of the "tulip" flame is still leaner with plasma assistance.
}
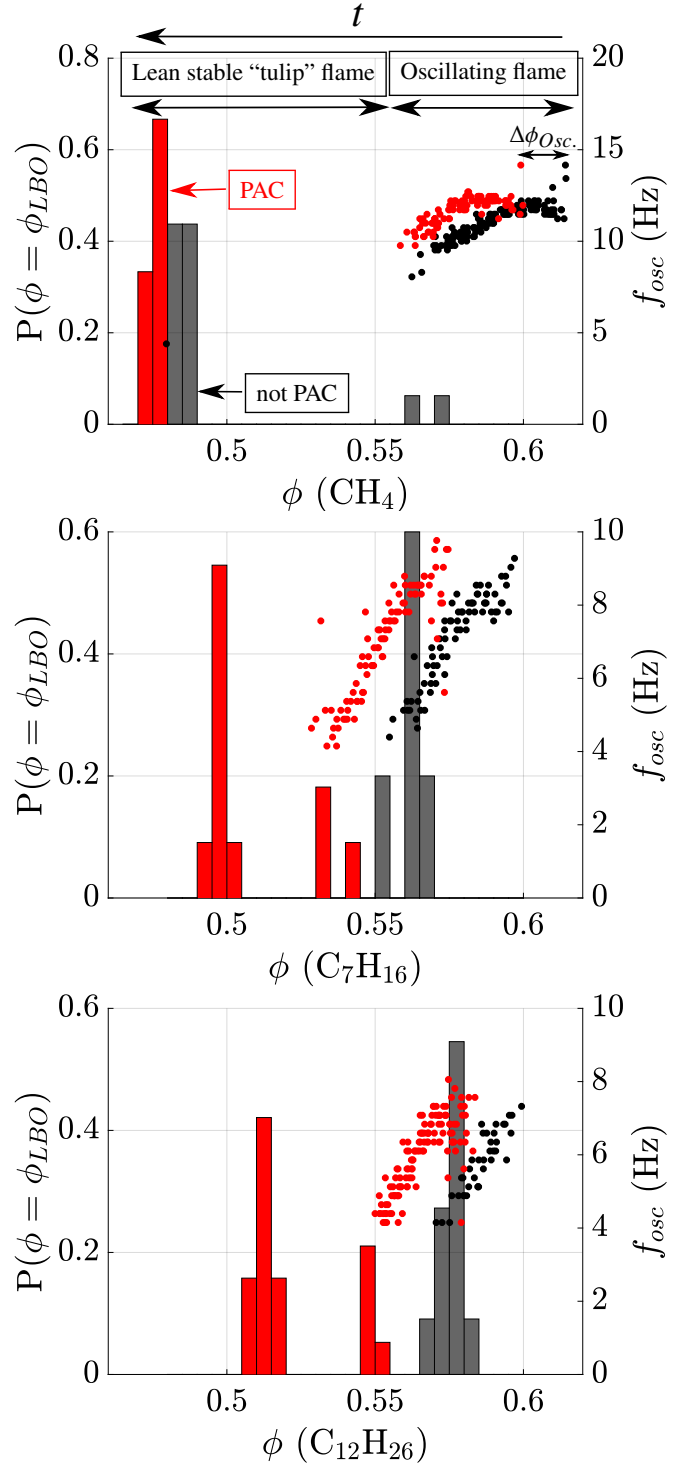

Figure 7: Probability of extinction (histogram, left axis) and frequency of oscillation (dots, right axis) as a function of equivalence ratio. Experiments with (red) and without (black) plasma assistance are shown. For each experiment, a spectrogram of the $\mathrm{OH}^{*} \mathrm{PM}$ signal is computed, and during the oscillation phase depicted in Fig. 6 , a strong peak at low frequency is visible. Each dot represents this peak frequency for an experiment, computed on a window of $1 \mathrm{~s}$, and only during the oscillation phase. The periodogram is computed using short-time Fourier transform with a frequency resolution of $0.25 \mathrm{~Hz}$ and a temporal resolution of $0.5 \mathrm{~s}$. This approach allows for a clear identification of the limits and frequency of the flame oscillations as a function of $\phi$. 


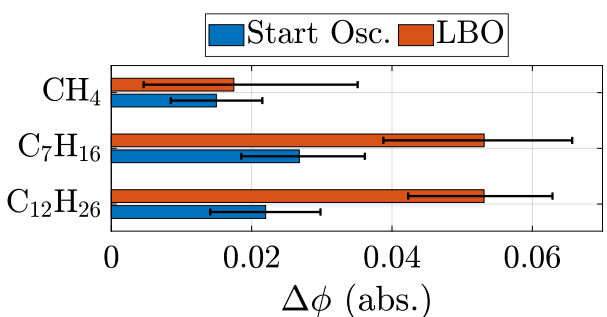

Figure 8: Shift in equivalence ratio, $\Delta \phi$, at LBO (brown) and at the start of the oscillations (blue), when NRP discharges are applied. Higher values indicate a stronger, more positive, effect of the plasma assistance. The uncertainty intervals are estimated from the repeatability of the mass flow controllers and from bootstrapping.

tion is also delayed by $\Delta \phi \approx 0.02$ for all three fuels.

At this point, it is useful to briefly compare these values with the results of other studies of the improvement of the LBO limit by PAC in similar combustors (premixed $\mathrm{CH}_{4}$-air swirling flames at atmospheric pressure). In [19], a variable swirl injector is used with a continuous microwave plasma discharge. The flame shape differs significantly from that of SICCA-Spray and, without plasma-assistance, LBO occurs between $0.85<\phi_{L B O}<1.3$ (depending on the flow rate). Using PAC with an electrical to thermal power ratio of $9 \%$ yields a $43 \%$ improvement on $\phi_{L B O}$ in their configuration. However comparison with the present work is not possible given the difference in flame and flow topologies. The combustor used in [5] is closest to SICCASpray. The flame shapes and LBO limits $\left(0.5<\phi_{L B O}<\right.$ 0.54 without PAC) are also similar. Using a dielectric barrier discharge applied continuously, the LBO is reduced down to $0.45<\phi_{L B O}<0.48$ in [5], which is comparable with results of the present work. In [6], a two-stage coaxial swirling injector (propane-air) is used with NRP discharges. The LBO performance significantly depends on the air flow split between the two stages of the injector, the primary stage acting as a pilot flame. At a low power setting, PAC reduces $\phi_{L B O}$ for the primary stage from 2 to 0.55 , a value close to what is observed in the present study.

\section{Impact of the Electrode Position}

As already indicated it is not possible to operate the discharges at $r / r_{i n j}<1$, because they would damage the liquid fuel atomizer head. Figure 9 shows the results obtained by varying the radial position of the electrode and measuring the LBO limit from repeated experiments with heptane. $r / r_{i n j}=6$ is optimal for this test rig in terms of effectiveness and repeatability. This

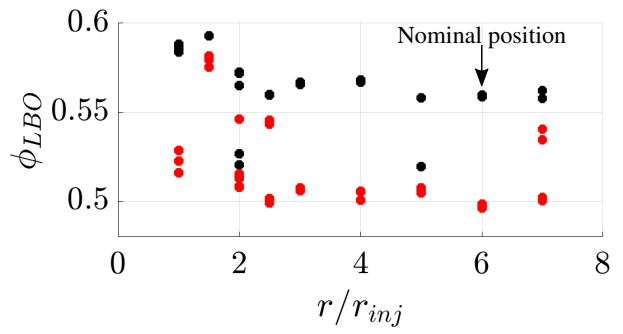

Figure 9: For the experiments presented in this figure, the radial position of the electrode is varied between $r=r_{i n j}=4 \mathrm{~mm}$ and $r=7 r_{i n j}=28 \mathrm{~mm}$. The dots indicate for each electrode position the global equivalence ratio at blow out $\phi_{L B O}$ with (red) and without (black) PAC. Each dot corresponds to a single experiment.

may be linked to the structure of the flame, to the associated flow and more specifically to the location of the ORZ. The typical shape of a heptane flame at $\phi=0.63$ is "M+ORZ" (see Fig. 1). From this pattern and from previously measured velocity profiles (in nonreactive, unconfined conditions [20], and in reactive, confined and steady conditions [29]), one may infer that near the combustor backplane the ORZ extends from $r / r_{i n j}=3$ to $r / r_{i n j}=6$. This region is filled with hot gases at relatively low velocity and turbulent intensity, with an augmented residence time, and a longer convective delay to the base of the flame. In the outer region, beyond $6 r_{i n j}$ the flow is cooled down by the wall. Between the injector rim and $r / r_{i n j}=2$ the flow is relatively fast, cold and turbulent. It is suggested by [18] that an electrode placement in a relatively slow recirculation zone will favor plasma induced chemical effects. This explains why the electrode location at $r / r_{i n j}=6$ provides the best performance in terms of LBO improvement.

\section{Conclusion}

This study is focused on the extension of the lean blow out (LBO) limit by NRP discharges in spray and perfectly premixed swirled flames at atmospheric pressure. Both liquid (heptane and dodecane) and gaseous (methane) fuels are examined. For these experiments, the fuel flow rate is kept constant, and the air flow rate is slowly increased until LBO occurs. The NRP discharges are applied at $20 \mathrm{kHz}$ and the ratio of electrical to thermal power is $2 \%$. Three phases are identified in the blow out sequence: the first stage sees flames initially in a "V" or " $M$ " shape burning further out in the outer recirculation zone (ORZ). In the second phase, the flames oscillate at a low frequency. Perfectly premixed flames stabilize in a "tulip" shape after the oscillations (third phase), until LBO occurs. For these flames, LBO 
occurs at a leaner condition with the use of NRP discharges. For non-assisted spray flames, LBO systematically occurs during the oscillations. If NRP discharges are used, spray flames can be stabilized in a "tulip" shape beyond the region where oscillations occur. The LBO limit is thereby greatly extended. The position of the electrode is identified as a critical factor for the effectiveness of the PAC system. The outer edge of the ORZ is found to be the most favorable location, both in terms of LBO performance and ease of placement in many practical systems.

\section{Acknowledgments}

Support is provided by France's ANR (FASMIC ANR16-CE22-0013; PASTEC ANR16-CE22-0005) and the EU Horizon2020 ANNULIGHT program (765998).

\section{References}

[1] S. K. Dhanuka, J. E. Temme, J. F. Driscoll, Lean-limit combustion instabilities of a lean premixed prevaporized gas turbine combustor, Proc. Combust. Inst. 33 (2) (2011) 2961 - 2966.

[2] J. K. Lefkowitz, P. Guo, T. Ombrello, S. H. Won, C. A. Stevens, J. L. Hoke, F. Schauer, Y. Ju, Schlieren imaging and pulsed detonation engine testing of ignition by a nanosecond repetitively pulsed discharge, Combust. Flame 162 (6) (2015) 2496-2507.

[3] D. A. Lacoste, J. P. Moeck, D. Durox, C. Laux, T. Schuller, Effect of nanosecond repetitively pulsed discharges on the dynamics of a swirl-stabilized lean premixed flame, J. Eng. Gas Turb. Power 135 (10) (October 2013).

[4] W. Kim, J. Snyder, J. Cohen, Plasma assisted combustor dynamics control, Proc. Combust. Inst. 35 (3) (2015) 3479-3486.

[5] G. T. Kim, C. S. Yoo, S. H. Chung, J. Park, Effects of non-thermal plasma on the lean blowout limits and $\mathrm{CO} / \mathrm{NOx}$ emissions in swirl-stabilized turbulent lean-premixed flames of methane/air, Combust. Flame 212 (2020) 403-414

[6] S. Barbosa, G. Pilla, D. A. Lacoste, P. Scouflaire, S. Ducruix, C. O. Laux, D. Veynante, Influence of nanosecond repetitively pulsed discharges on the stability of a swirled propane/air burner representative of an aeronautical combustor, Philos. Trans. R. Soc. A 373 (2048) (2015) 20140335.

[7] A. Starikovskiy, N. Aleksandrov, Plasma-assisted ignition and combustion, Prog. Energ. Combust. 39 (1) (2013) $61-110$.

[8] S. Starikovskaia, Plasma-assisted ignition and combustion: nanosecond discharges and development of kinetic mechanisms, J. Phys. D: Appl. Phys. 47 (15) (2014) 353001.

[9] I. Adamovich, W. Lempert, Challenges in understanding and predictive model development of plasma-assisted combustion, Plasma Phys. Controlled Fusion 57 (1) (2014) 014001

[10] Y. Ju, J. Lefkowitz, C. Reuter, S. Won, X. Yang, S. Yang, W. Sun, Z. Jiang, Q. Chen, Plasma assisted low temperature combustion, Plasma Chem. Plasma Process. 36 (2016) 85-105.

[11] C. Dumitrache, A. Gallant, N. Minesi, S. Stepanyan, G. D. Stancu, C. O. Laux, Hydrodynamic regimes induced by nanosecond pulsed discharges in air: mechanism of vorticity generation, J. Phys. D: Appl. Phys. 52 (36) (2019) 364001.
[12] D. L. Rusterholtz, D. A. Lacoste, G. D. Stancu, D. Z. Pai, C. O. Laux, Ultrafast heating and oxygen dissociation in atmospheric pressure air by nanosecond repetitively pulsed discharges, J. Phys. D: Appl. Phys. 46 (46) (2013) 464010.

[13] D. Z. Pai, D. A. Lacoste, C. O. Laux, Transitions between corona, glow, and spark regimes of nanosecond repetitively pulsed discharges in air at atmospheric pressure, J. Phys. D: Appl. Phys. 107 (9) (2010) 093303.

[14] M. S. Bak, S.-K. Im, M. G. Mungal, M. A. Cappelli, Studies on the stability limit extension of premixed and jet diffusion flames of methane, ethane, and propane using nanosecond repetitive pulsed discharge plasmas, Combust. Flame 160 (11) (2013) $2396-2403$

[15] M. A. Boumehdi, S. A. Stepanyan, P. Desgroux, G. Vanhove, S. M. Starikovskaia, Ignition of methane- and n-butanecontaining mixtures at high pressures by pulsed nanosecond discharge, Combust. Flame 162 (4) (2015) 1336-1349.

[16] D. A. Xu, D. A. Lacoste, C. O. Laux, Ignition of Quiescent Lean Propane-Air Mixtures at High Pressure by Nanosecond Repetitively Pulsed Discharges, Plasma Chem. Plasma Process. 36 (1) (2016) 309-327.

[17] G. Pilla, D. Galley, D. Lacoste, F. Lacas, D. Veynante, C. Laux, Stabilization of a turbulent premixed flame using a nanosecond repetitively pulsed plasma, IEEE Trans. Plasma Sci. 34 (6) (2006) 2471-2477.

[18] C. Kong, Z. Li, M. Aldén, A. Ehn, Stabilization of a turbulent premixed flame by a plasma filament, Combust. Flame 208 (2019) $79-85$.

[19] R. Rajasegar, C. M. Mitsingas, E. K. Mayhew, S. Hammack, H. Do, T. Lee, Effects of continuous volumetric direct-coupled nonequilibrium atmospheric microwave plasma discharge on swirl-stabilized premixed flames, IEEE Trans. Plasma Sci. 44 (1) (2016) 39-48.

[20] K. Prieur, D. Durox, J. Beaunier, T. Schuller, S. Candel, Ignition dynamics in an annular combustor for liquid spray and premixed gaseous injection, Proc. Combust. Inst. 36 (3) (2017) 3717-3724.

[21] N. Minesi, S. A. Stepanyan, P. B. Mariotto, G.-D. Stancu, C. O. Laux, Fully ionized nanosecond discharges in air: the thermal spark, Submitted to Plasma Sources Sci. Technol. (2020).

[22] R. Maly, M. Vogel, Initiation and propagation of flame fronts in lean $\mathrm{CH} 4$-air mixtures by the three modes of the ignition spark, Symp. (Int.) Combust. 17 (1) (1979) 821-831.

[23] C. O. Laux, T. G. Spence, C. H. Kruger, R. N. Zare, Optical diagnostics of atmospheric pressure air plasmas, Plasma Sources Sci. Technol. 12 (2003) 125-138.

[24] A. G. Gaydon, The Spectroscopy of Flames, Springer Netherlands, 1974.

[25] W. Kim, H. Do, M. G. Mungal, M. A. Cappelli, Plasmadischarge stabilization of jet diffusion flames, IEEE Trans. Plasma Sci. 34 (6) (2006) 2545-2551.

[26] M. A. Gigosos, M. Á. González, V. Cardeñoso, Computer simulated Balmer-alpha, -beta and -gamma Stark line profiles for non-equilibrium plasmas diagnostics, Spectrochim. Acta B 58 (8) (2003) 1489-1504.

[27] A. H. Lefebvre, Atomization and Sprays, CRC Press, 1989.

[28] P. J. Schmid, Dynamic mode decomposition of numerical and experimental data, J. Fluid Mech. 656 (2010) 5-28.

[29] T. Lancien, Numerical study of two-phase ignition in annular multi-burner combustors, Ph.D. thesis, Université Paris-Saclay. 